\title{
Efficiency Enhancement of an Open Cathode Fuel Cell through a Systemic Management
}

\author{
M. Kandidayeni, Student Member, IEEE, A. Macias, Student Member, IEEE, L. Boulon, Senior \\ Member, IEEE, S. Kelouwani, Senior Member, IEEE
}

\begin{abstract}
This paper addresses the design of a systemic management to improve the energetic efficiency of an open cathode proton exchange membrane fuel cell (PEMFC) in a hybrid system. Unlike the other similar works, the proposed approach capitalizes on the usage of both thermal management strategy and current control to meet the requested power from the system by the minimum fuel consumption. To do so, firstly, an experimentally based 3D mapping is performed to relate the requested power form the PEMFC to its operating temperature and current. Secondly, the reference temperature which leads to gaining the demanded power by the minimum current level is determined to minimize the hydrogen consumption. Finally, the temperature control is formulated by an optimized fuzzy logic scheme to reach the determined reference temperature by acting on the cooling fan of the PEMFC system, whilst the current is being regulated by its controller. The inputs of the fuzzy controller are the PEMFC current and temperature error and the sole output is the duty factor of the fan. The proposed methodology is tested on an experimental test bench to be better evaluated in a real condition. The obtained results from the proposed systemic management indicate promising enhancement of the system efficiency compared to a commercial controller. The proposed method of this work is extendable and applicable in fuel cell hybrid electric vehicles.
\end{abstract}

Index Terms-Fuel cell efficiency improvement, fuzzy logic control, optimization, power mapping, systemic management, thermal management strategy.

\section{INTRODUCTION}

$\mathrm{P}$ roton exchange membrane fuel cell (PEMFC) is perceived as a promising technology for green and efficient generation of power in stationary and transportation applications [1]. In the literature, the performance of a PEMFC has been improved by concentrating on two principles of

This work was supported in part by the Natural Sciences and Engineering Research Council of Canada (NSERC), the Fonds de recherche du Québec Nature et technologies (FRQNT), and Canada Research Chairs program.

M. Kandidayeni, and A. Macias, are with the Hydrogen Research Institute, Department of Electrical and Computer Engineering, Université du Québec à Trois-Rivières, QC G8Z 4M3, Canada (email: mohsen.kandi.dayeni@uqtr.ca, and alvaro.omar.macias.fernandez@uqtr.ca).

L. Boulon is with the Hydrogen Research Institute, Department of Electrical and Computer Engineering, Université du Québec à Trois-Rivières, QC G8Z 4M3, Canada (e-mail: loic.boulon@uqtr.ca ).

S. Kelouwani is with the Hydrogen Research Institute, Department of Mechanical Engineering, Université du Québec à Trois-Rivières, QC G9A 5H7, Canada (e-mail: sousso.kelouwani@uqtr.ca). membrane electrode assembly design and system design. The first one includes modifying the material and structural properties of the gas diffusion layer, cathode catalyst layer, and membrane to operate in the existence of liquid water [2-4]. The second one involves proper flow field design of channels, which can upgrade the performance in a passive manner by, for instance, balancing the cooling fan effects and air flow for reaching complete reactions at the cathode leading also to a better water balance. Moreover, it includes operating condition control, anode water removal, and electro-osmotic pumping [5, 6]. The output power of the PEMFC is dependent on different operating points such as temperature, current, and pressure [79]. Regarding the PEMFC as a system provides several degrees of freedom in terms of supplying the power due to the fact that the mentioned operating points, which are influential in the performance of the PEMFC, can come under control in this way. A specific level of demanded power can be supplied by different combinations of these operating conditions and how to go towards selecting the right combination for having an efficient performance is the goal of this work. The temperature of a PEMFC stack has an impact on the electrochemical, thermodynamics, electro-kinetics, transport, and water distribution processes, which jointly dictate system efficiency and long-term durability [10]. This is significant in all sorts of PEMFCs and operating modes, but is chiefly relevant to airbreathing/cooled PEMFCs where the input air is responsible for both reactant and cooling the system [11]. The increase of the fan speed enhances the reactant supply, decreases the temperature (depending on the ambient temperature), and may also lead to a dry membrane (depending on the air humidity). The combination of these three effects can result in various impacts on power and hydrogen consumption which are difficult to highlight with an analytical model. The proton exchange membrane and the ionomer in the porous catalyst layers of this type of PEMFC need the presence of a particular amount of water to ensure satisfactory protonic conductivity. The water content in the ionomer of the membrane and catalyst layers is deeply affected by the operating temperature of the stack. The dynamics of water absorption of the ionomer and the diffusion of water across the membrane are both dependent on the stack temperature as discussed in $[12,13]$. In fact, the temperature influence over the water transport in the catalyst layers is primarily premised on the absorption and desorption of water in the ionomer as well as the condensation and evaporation in the pores. As discussed in [14], the active area of membrane is directly affected by the water content in the catalyst layer. If the catalyst layer becomes dry owing to the water drain from its pores, less protons arrive at the active sites 
for the electrochemical reaction with the reactant gases and the electrons. This phenomenon in turn diminishes the PEMFC performance [15]. In this respect, the optimal management of temperature is critical in open cathode PEMFCs to avoid the occurrence of the discussed phenomena and enhance the efficiency of the system. In each power level, a reference value for the temperature and current can be assigned to acquire the optimal efficiency, by the assumption of having a constant pressure. This reference value is like an equilibrium point in which all the influential operating conditions are stable. Another important factor which particularly influences the performance of an open cathode PEMFC is the cooling fan operation which has a vital role in the occurrence of drying and flooding and also electrochemical reactions [16].

Several researches have been conducted on the temperature regulation of a PEMFC system. Many of these studies have used PID controllers for thermal management. The temperature behavior of a closed-cathode PEMFC equipped with liquid cooling is controlled through a feedback PID control in [17], and a PI controller in $[18,19]$. A standard PID controller along with an ON/OFF switch are used for thermal management in a 3-kW water-cooled PEMFC in [20]. A state feedback control [21] is compared in simulation with a model reference adaptive control in terms of regulating the temperature of a closedcathode PEMFC and concluded that the second method shows more robustness in [22]. In [23, 24], two controllers based on active disturbance rejection are proposed to regulate the temperature of a closed-cathode and an open-cathode PEMFC respectively. Both of these controllers have shown successful performance in simulation. In [25], a 500-W open-cathode PEMFC model is studied in which the temperature is controlled by an on-off strategy.

Literature consideration indicates that most of the discussed papers are fundamentally premised on simulation and furthermore, very few works have focused on open cathode PEMFCs. In [26, 27], the performance of two fuzzy logic controllers (FLCs) have been compared with PID controllers on an experimental test bench regarding the temperature regulation of a $2000-\mathrm{W}$ and a $100-\mathrm{W}$ open cathode PEMFC respectively. The authors have shown that the PID controllers cause large temperature overshoot in different operating conditions compared to the FLC. Two reasons can be given to explain the overshoot problem. First, PID controllers work well for a limited operating range. Second, their adjustment is dependent on the accuracy of the model, which is an ongoing research domain in the PEMFC area. Therefore, FLC seems to be a good choice since it shows better flexibility in a wide range of operation while working with not very accurate models.

Another worth reminding aspect is that very few works have tried to propose a methodology to create a link between the temperature control and the operating point tracking of a PEMFC, such as maximum power and efficiency points. These operating conditions are abundantly used in vehicular applications [28-30], and they are only conceivable in particular stable operating temperature. In [31], a simple single-input single-output FLC is used to control the temperature for finding the maximum efficiency point of an open cathode PEMFC. In the majority of the existent maximum operating point tracking methods, from perturb and observe and step size methods [32, $33]$ to identification techniques coupled with an optimization method [34-38], the PEMFC has been considered as just a component in which the only reference signal (control variable) is the operating current by assuming constant temperature and/or pressure. However, PEMFC is a system, and several local controls should be defined over this system to reach the desired condition.

This paper presents a methodology to formulate a systemic management for an open cathode PEMFC. The main contribution of this work is to simultaneously control temperature and current with the goal of supplying the requested power from the PEMFC system with a high level of efficiency. To do so, two important stages of management, to determine the reference signals, and control, to reach them, are required. In the proposed systemic management, depending on the requested power level, a reference temperature is extracted through a generated $3 \mathrm{D}$ power map which enables the supply of the power with the lowest current. The lower the current level, the lower the hydrogen consumption. Subsequently, an optimized FLC is used to reach the assigned reference temperature, while the current of the PEMFC is controlled by a PI controller. In contrast to [26, 27] in which the FLCs have been adjusted by many trials and errors, the utilized FLC is tuned by a hybrid optimization algorithm in this paper. The FLC is first tested on a PEMFC model before implementation on the test bench. The remainder of this manuscript is organized as follows:

Section II deals with the process of obtaining the power map. Determining the reference operating point is dealt with in section III. Section IV describes the formulation of the optimized fuzzy controller. The results are discussed in section $\mathrm{V}$, and finally the conclusion is given in section VI.

\section{3D POWER MAPPING}

This section puts forward an experimental framework to determine the output power of a PEMFC by considering the influence of operating current, temperature, and cooling fan duty factor while the air pressure is constant in this set-up. To do so, two steps of data collection, and power map generation are required as shown in Fig. 1. Initially, some tests need to be conducted on the open cathode PEMFC to analyze the influence of operating current and duty factor over the stack temperature. The presented test bench in Fig. 2 is used to perform all the experiments in this work.

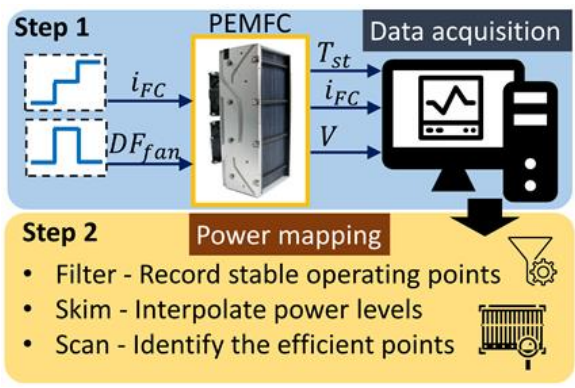

Fig. 1. Experimental procedure for generating the power map. 
The utilized fuel cell system in this set-up is the commercially available 500-W PEMFC with 36 cells from Horizon Fuel Cell Technologies. This open-cathode PEMFC is self-humidified and air- cooled. It has two axial cooling fans straightly connected to the housing, which decrease the temperature of the stack by forced convection and in the same time provides oxygen to the cathode. As it is seen, the opencathode PEMFC is connected to a National Instrument CompactRIO through a controller. A DC electronic load is utilized to request current profiles from the PEMFC. According to the manual of the system, the difference between the atmospheric pressure in the cathode side and the pressure of the PEMFC in the anode side should be $50.6 \mathrm{kPa}$. The pressure in the anode side is set to $55.7 \mathrm{kPa}$. The temperature and voltage of the real PEMFC are measured and transferred to the PC with the help of CompactRIO to be used in the control process. The PC and CompactRIO communicate by means of an Ethernet connection every 100 milliseconds. It is worth mentioning that the proposed methodology of this work is expandable to other PEMFC types with higher or lower power rates due to its datadriven foundation.

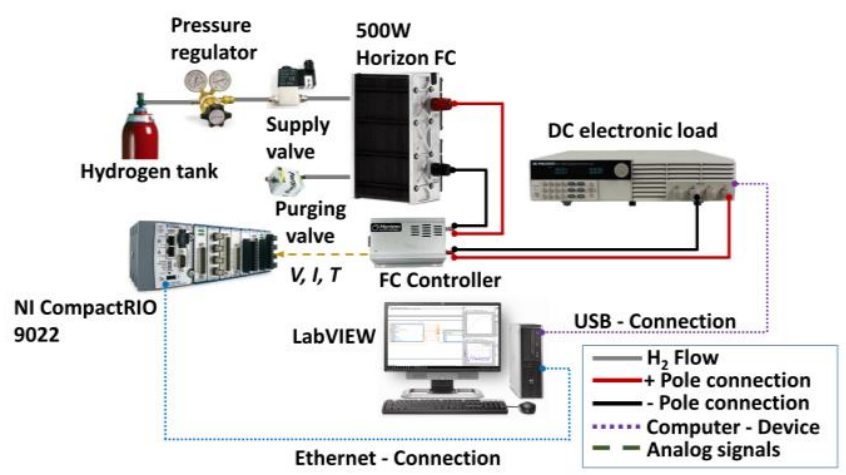

Fig. 2. The developed test bench in Hydrogen Research Institute.

To acquire the necessary data for power mapping, a ramp-up current profile, as shown in Fig. 3a, is applied to the PEMFC system in five different fan duty factors, namely $0.25,0.34,0.5$, 0.7 , and 1 . At each level of fan duty factor, the test is continued
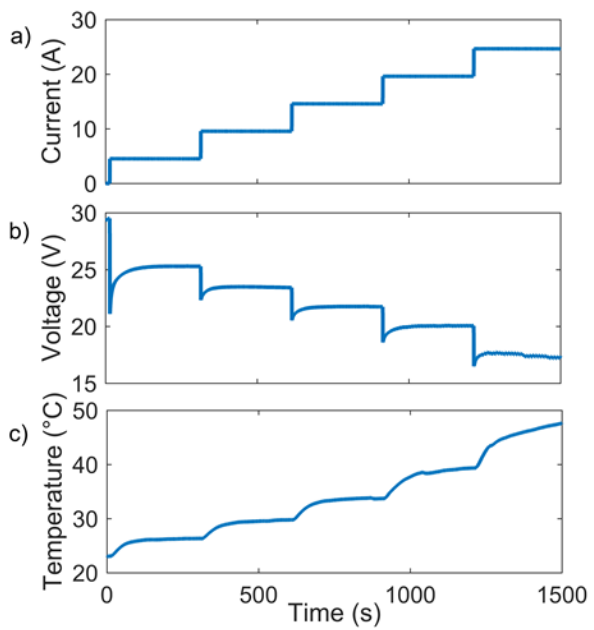

Fig. 3. Ramp-up current profile (a) and its corresponding recorded voltage (b) and temperature (c). until the maximum power of the PEMFC is achieved, and the voltage drop due to the concentration loss is observed. After completing the test, the recorded stable points of the PEMFC stack (current, voltage, and temperature), as shown in Fig. 3, are used to plot the map. Since the chosen current and fan duty factors contain the minimum and maximum levels, the acquired map covers almost all the operating conditions.

Fig. 4 characterizes the influence of cooling fan and current on the stack temperature of the PEMFC. This figure has been generated by using the collected data from the conducted experiments. Fig. 5 presents the obtained power map from the experimental measurements. This power map is used in the process of determining the reference temperature for the systemic management process.

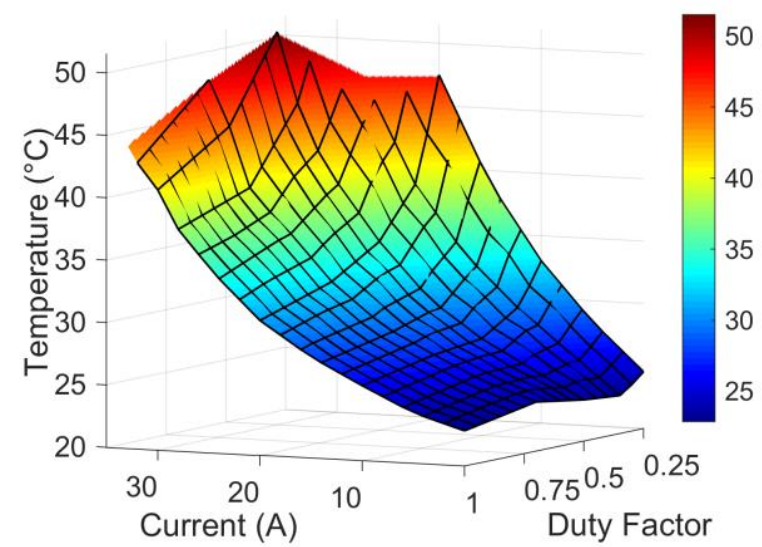

Fig. 4. Influence of operating current and fan duty factor over the stack temperature.

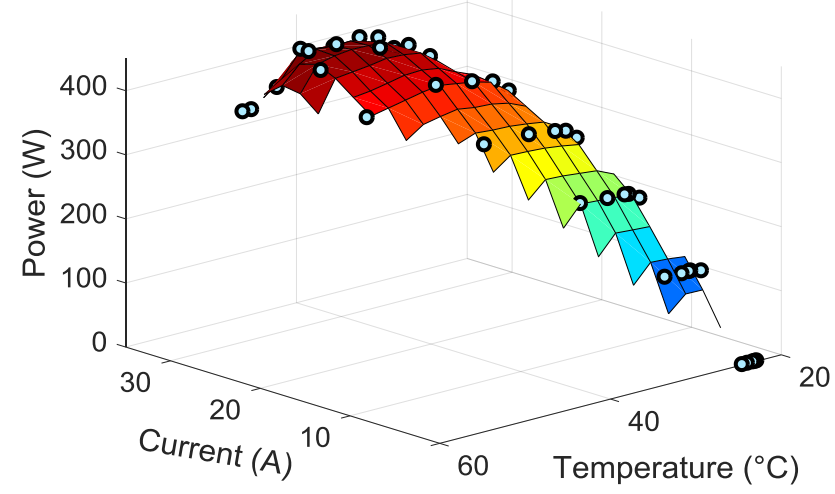

Fig. 5. Generated power map from experimental data

\section{REFERENCE OPERATING POINT DETERMINATION}

As shown in Fig. 5, a given power can be reached by using several operating points like temperature and current. So, a degree of freedom remains. In this work, current and temperature are considered as the main variables and the objective is to meet a requested power while minimizing the hydrogen consumption of the system. Fig. 6, which has been obtained by doing some experiments on the real PEMFC, indicates two important interdependences. First, the relation of hydrogen consumption with respect to the operating current and fan duty factor, and second, the influence of the fan duty factor 
over the operating range of the PEMFC stack in terms of current. As is seen in this figure, hydrogen consumption is significantly dependent on the operating current of the stack rather than the fan duty factor. However, fan duty factor plays an important role in determining the range of the stack operating current where lower duty factors lead to limited operating ranges and higher duty factors extend the range of stack operation.

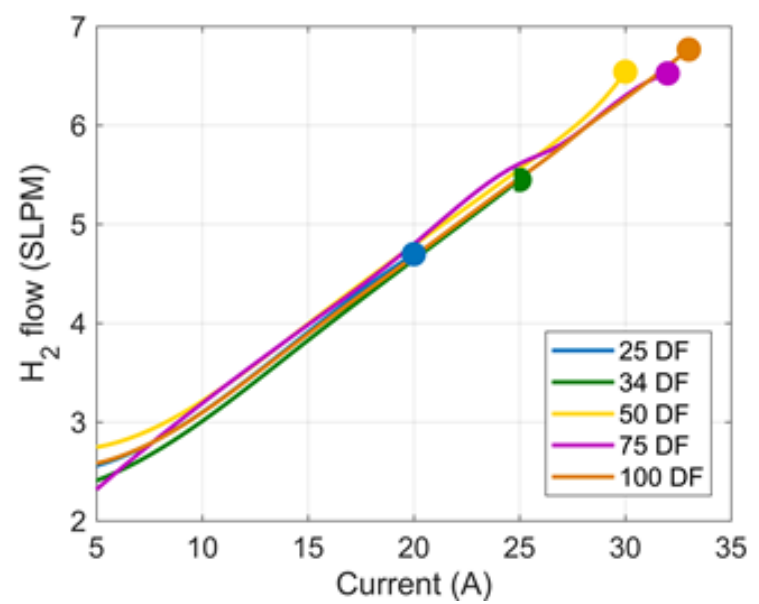

Fig. 6. Effect of current and cooling fan duty factor on the hydrogen consumption and operating range of the stack.

The behavior of the hydrogen molar flow $\left(f_{H 2}\right)$ can be estimated by (1) [39]:

$$
f_{H 2}=a i_{f c}+b D F_{f a n}+c
$$

Where $i_{f c}$ is the PEMFC operating current (A) and $D F_{f a n}$ is the cooling fan duty factor.

Fig. 7 represents the 2D power map attained through the explained methodology by doing interpolation. For each power,

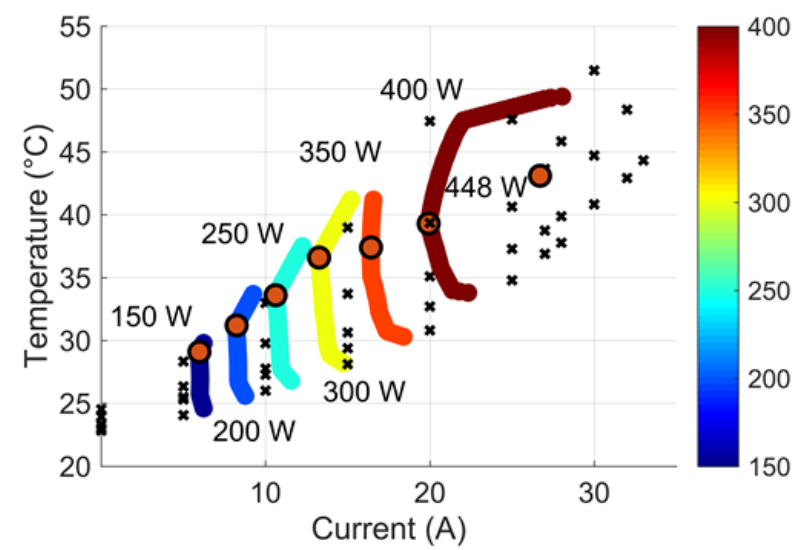

Fig. 7. 2D demonstration of PEMFC power map for different levels of temperature and current.

the best operating point (temperature and current) in terms of $\mathrm{H} 2$ consumption is highlighted by a circle. These points lead to an optimal path to reach the requested power by minimizing the $\mathrm{H} 2$ consumption. The presented power map belongs to the fuel cell system, which means that the auxiliary power consumptions such as valves and the fan have been subtracted from the stack power. This map also shows that a specific function can be generated to relate the power and optimal temperature. This relation is represented in Fig. 8 and is used to determine the reference temperature of the controller to match the requested power and the minimal hydrogen consumption. Providing such experimental basis guaranties that the controller leads to a high efficiency region at each specific power level.

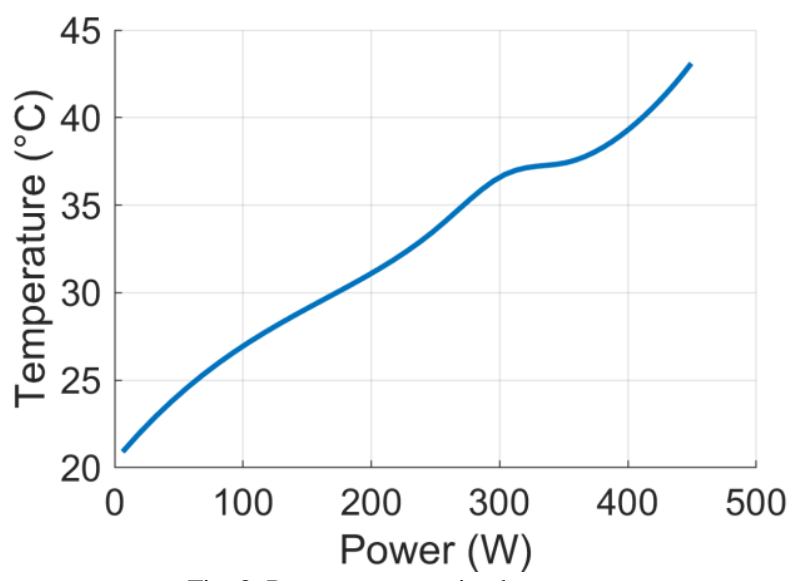

Fig. 8. Power versus optimal temperature.

Fig. 9 confirms that each selected optimal point, presented in the power map of Fig. 7, corresponds to the minimum hydrogen consumption and mathematically the interpolated lines in each power level can be considered as a convex problem which has only one minimum. It should be noted that one of the advantages of the proposed method for determining the reference temperature is that it is easily updatable with respect to the performance drifts of the PEMFC stack arising from the ambient conditions variation and even ageing phenomenon. In this respect, the map can be easily updated by recording some stable points (current, voltage, and temperature) from different operation zones of the PEMFC stack and using them for generating a new map with the commonly used least square approaches.

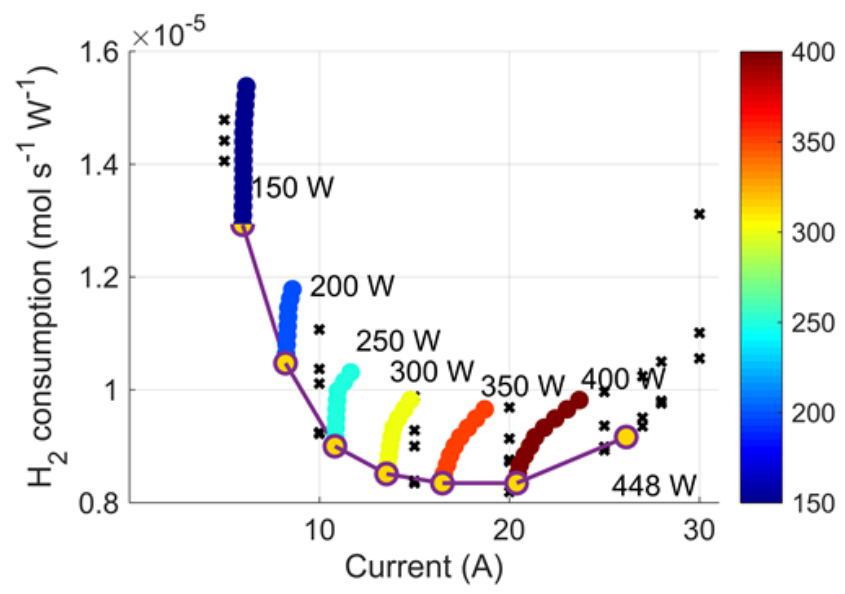

Fig. 9. Hydrogen consumption and required current for each specific power level. 


\section{TEMPERATURE AND CURRENT CONTROL}

The general structure of the temperature and current control is presented in Fig. 10. As it is seen, in a hybrid system, the PEMFC deals with supplying the average power and the dynamic part is left to the battery pack or other energy storage systems. For each requested power level from the PEMFC system, a specific $T_{\text {ref }}$ is set through the obtained 2D power map. This $T_{r e f}$ is imposed to a FLC which acts on the cooling fan to reach it. However, the temperature regulation is a slow dynamic process, contrary to the current control which is very fast. In this regard, while the FLC is trying to regulate the temperature, a PI power controller is used to give the PEMFC system enough relaxation time for efficient supply of the power by gaining the $T_{r e f}$ which corresponds to the minimum current. As the FLC increases or decreases the temperature to reach the set point, depending on the initial stack temperature, the PI controller regulates the PEMFC current in a way to track the requested power.

The explained FLC for temperature regulation of the PEMFC uses the temperature error and the reference current of the PEMFC as inputs and determines the fan duty factor as the output. The obtained fan duty factor from the FLC is sent to the real PEMFC to warm up or cool down the system. The temperature error is the difference between the stack temperature and the reference temperature obtained from the explained power map. The reference current signal, which strikingly influences the PEMFC stack performance, is determined by a PI controller. The input of the PI controller is the error between the requested power from PEMFC and the supplied power by PEMFC, and the output is the current, which will be the input of the fuzzy controller. Using this PI regulator ensures that the requested power is met. The characteristics of the FLC are as follows: inference engine is AND (minimum operator), diffuzication is centroid, and fuzzy system type is Mamdani. Table I specifies the fuzzy reasoning rules.

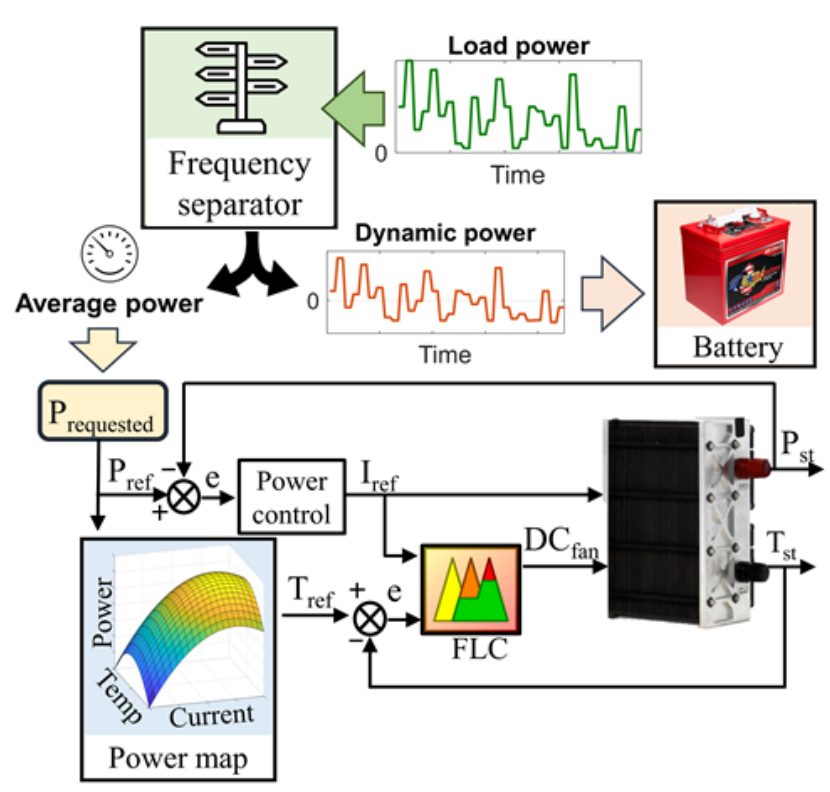

Fig. 10. Configuration of the systemic temperature and current management and control.
TABLE I

FUZZY REASONING RULES

\begin{tabular}{|c|c|c|c|}
\hline \hline Hot & Very Fast & Very Fast & Very Fast \\
\hline Warm & Average & Fast & Very Fast \\
\hline Normal & Slow & Slow & Fast \\
\hline Cold & Very Fast & Slow & Slow \\
\hline Very Cold & Very Fast & Very Fast & Slow \\
\hline \hline
\end{tabular}

\section{A. Fuzzy optimization}

Since the distribution of input membership functions (MFs) has been considered as consistent over the universe of discourse, the FLC might not perform optimally over various operating conditions of the PEMFC. In this regard, instead of conducting several trials to define the boundaries of the input MFs, they are tuned by means of a hybrid optimization algorithm composed of particle swarm optimization and genetic algorithm (PSO-GA). However, before going through the optimization process, a PEMFC model, capable of imitating the real-behavior of the stack, is needed to be used in the tuning process of the FLC parameters. This is due to the fact that utilizing the real PEMFC stack for performing the optimization process damages its state of health. Hereinafter, firstly, the employed PEMFC model for the optimization process is described. Subsequently, the utilized PSO-GA algorithm and its controlling parameters are explained in details.

\section{1) PEMFC stack model}

In this work, a model made up of an electrochemical and a thermal sub-model is employed to imitate the behavior of an open cathode PEMFC. The utilized model, which is shown in Fig. 11, is able to mimic the PEMFC behavior in steady-state and low-dynamic conditions.

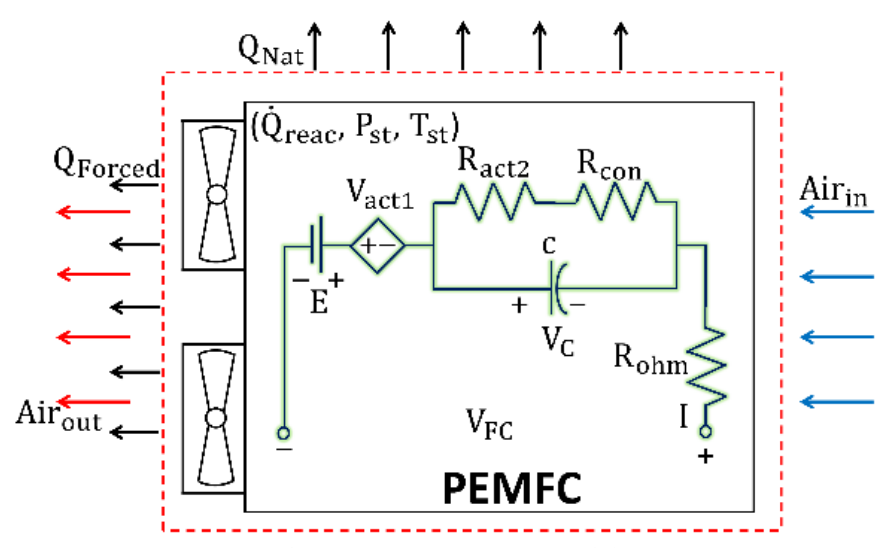

Fig. 11. PEMFC system model.

\section{- Electrochemical model}

The electrochemical model is based on the Amphlett et al. model which has been justified in several studies [34, 35]. This model, which is shown in Fig. 11 in the form of an electrical circuit, includes the polarization effects. The charge double layer phenomenon has been added to this model based on [40, 
41]. The output voltage of the PEMFC, which is for a number of cells connected in series, is obtained by:

$V_{F C}=N\left(E_{\text {Nernst }}+V_{\text {act } 1}+V_{C}+V_{\text {ohmic }}\right)$

where $V_{F C}$ is the output voltage $(\mathrm{V}), N$ is the number of cells, $E_{\text {Nernst }}$ is the reversible cell potential $(\mathrm{V}), V_{C}$ is the doublelayer charging effect, $V_{\text {ohmic }}$ is the ohmic loss $(\mathrm{V})$, and $V_{\text {act }}$ is the activation loss $(\mathrm{V})$. Activation loss is composed of a drop related to the PEMFC internal temperature $\left(V_{a c t 1}\right)$ and a drop related to the both current and temperature of the stack $\left(V_{a c t 2}\right)$. The reversible cell potential is calculated by:

$E_{\text {Nernst }}=1.229-0.85 \times 10^{-3}\left(T_{s t}-298.15\right)+4.3085 \times$

$10^{-5} T_{s t}\left[\ln \left(P_{\mathrm{H} 2}\right)+0.5 \ln \left(P_{\mathrm{O} 2}\right)\right]$

where $T_{s t}$ is the stack temperature $(\mathrm{K}), P_{H 2}$ is the hydrogen partial pressure in anode side $\left(\mathrm{N} \mathrm{m}^{-2}\right)$, and $P_{O 2}$ is the oxygen partial pressure in cathode side $\left(\mathrm{N} \mathrm{m}^{-2}\right)$. The activation loss is given by:

$$
\begin{aligned}
V_{a c t} & =-\left[V_{a c t 1}+V_{a c t 2}\right] \\
V_{a c t 1} & =-\left[\xi_{1}+\xi_{2} T_{s t}+\xi_{3} T_{s t} \ln \left(C O_{2}\right)\right] \\
V_{a c t 2} & =-\left[\xi_{4} T_{s t} \ln (i)\right] \\
C_{2} & =P_{O 2} / 5.08 \times 10^{6} \exp \left(-498 / T_{s t}\right)
\end{aligned}
$$

where $\xi_{k}(\mathrm{k}=1 \ldots 4)$ are the semi-empirical coefficients based on fluid mechanics, thermodynamics, and electrochemistry, $\mathrm{CO}_{2}$ is the oxygen concentration $\left(\mathrm{mol} \mathrm{cm}^{-3}\right)$, and $i$ is the PEMFC operating current (A). The double-layer charging effect is formulated by:

$\left\{\begin{array}{l}V_{C}=(i-c d V / d t)\left(R_{\text {act } 2}+R_{\text {con }}\right) \\ R_{\text {act } 2}=V_{\text {act } 2} / i \\ R_{\text {con }}=V_{\text {con }} / i=\left(B \ln \left(1-J / J_{\text {max }}\right) / i\right)\end{array}\right.$

where $c$ is the equivalent capacitor due to the double-layer charging effect $(F)$, which is in order of several Farads because of porous electrodes of the PEMFC, $B$ is a parametric coefficient $(\mathrm{V}), J$ is the actual current density $\left(\mathrm{A} \mathrm{cm}^{-2}\right), J_{\max }$ is the maximum current density $\left(\mathrm{A} \mathrm{cm}^{-2}\right)$, and $V_{\text {con }}$ is the concentration loss $(\mathrm{V})$. The ohmic overvoltage can be described by:

$V_{\text {ohmic }}=-i R_{\text {internal }}=-i\left(\zeta_{1}+\zeta_{2} T_{\text {st }}+\zeta_{3} i\right)$

where $R_{\text {internal }}$ is the internal resistor $(\Omega)$, and $\zeta_{k}(\mathrm{k}=1 \ldots 3)$ are the parametric coefficients.

\section{- $\quad$ Thermal model}

The thermal behavior of the open cathode PEMFC is modeled by means of energy conservation equations for a lumped system, as introduced in [26, 27]. According to the energy conservation law, the energy balance for describing the temperature dynamic of the PEMFC can be given by:

$m_{s t} C_{s t} d T_{s t} / d t=\dot{Q}_{\text {reac }}-P_{s t}-Q_{N a t}-Q_{\text {Forced }}$ where $m_{s t}$ is stack mass $(4.2 \mathrm{~kg}), C_{s t}$ is specific heat capacity of stack (J/kg K) [27], $T_{s t}$ is stack temperature $(\mathrm{K}), \dot{Q}_{\text {reac }}$ is the released energy from electrochemical reaction $(\mathrm{J}), P_{s t}$ is the generated electrical power $(\mathrm{W}), Q_{N a t}$ is the natural convection $(\mathrm{J})$, and $Q_{\text {Forced }}$ is the forced convection ( $\left.\mathrm{J}\right)$. The obtained energy form electrochemical reaction and the produced electrical power of the stack can be presented by:

$\dot{Q}_{\text {reac }}=V_{\text {max }} i N$

$V_{\text {max }}=\Delta H / n F$

$P_{s t}=V_{F C} i$

where $V_{\max }$ is the maximum voltage obtained by hydrogen low heating value $(1.23 \mathrm{~V})$ or hydrogen high heating value $(1.48 \mathrm{~V})$, $\Delta H$ is the formation enthalpy, $n$ is the number of electrons per molecule, and $F$ is the Faraday's constant. The convective heat transfer, which is composed of natural and forced convection, can be formulated by:

$Q_{N a t}=h_{N a t} A_{N a t}\left(T_{s t}-T_{c a}\right)$

$Q_{\text {Forced }}=\alpha D_{\text {fan }} \rho_{\text {air }} A_{\text {Forced }} C_{p}\left(T_{s t}-T_{c a}\right)$

where $h_{N a t}$ is the natural heat transfer coefficient $\left(14 \mathrm{~W} / \mathrm{m}^{2} \mathrm{~K}\right)$ [26], $A_{\text {Nat }}$ is the total surface area of the $500-\mathrm{W}$ Horizon PEMFC $\left(0.1426 \mathrm{~m}^{2}\right)$ which has been calculated by the available dimensions in the manual of the device, $T_{c a}$ is the ambient temperature $(\mathrm{K}), \alpha$ is an empirical coefficient obtained by experiment, $D_{\text {fan }}$ is the fan duty factor, $\rho_{\text {air }}$ is the ambient air density $\left(1.267 \mathrm{~kg} / \mathrm{m}^{3}\right), A_{\text {Forced }}$ is the area exposed to the forced convection $(0.22 \mathrm{~m} \times 0.13 \mathrm{~m} \times 2)$, and $C_{p}$ is the air specific heat capacity $(1005 \mathrm{~J} / \mathrm{kg} \mathrm{K})$. The parameters which need to be tuned in the discussed electrochemical and thermal sub-models are listed in TABLE I. The values of these parameters have been obtained by GA from the Global Optimization Toolbox of Matlab using the measured experimental voltage, temperature, and current of the PEMFC.

To assess the capability of the developed PEMFC model in imitating the behavior of a 500-W Horizon PEMFC, the presented current profile in Fig. 12a has been applied to the model and the emulation results are compared with the measurements. Fig. 12b and Fig. 12c represent the voltage and temperature estimations respectively. As is seen in Fig. 12, the model is able to predict the PEMFC behavior with a satisfactory precision.

TABLE I PEMFC MODEL PARAMETERS

\begin{tabular}{cccc}
\hline \hline Model & Parameter & Value & $\begin{array}{c}\text { Reference for min. } \\
\text { and max. limits }\end{array}$ \\
\hline & $\xi_{1}$ & -1.29 & \\
$\xi_{2}$ & $3.2042 \times 10^{-3}$ & \\
$\xi_{3}$ & $2.60 \times 10^{-5}$ & \\
Electrochemical & $\xi_{4}$ & $-1.50 \times 10^{-6}$ & \\
& $c(\mathrm{~F})$ & 6.107 & {$[34,41]$} \\
& $B(\mathrm{~V})$ & 0.3513 & \\
& $\zeta_{1}$ & 0.00375 & \\
& $\zeta_{2}$ & $1 \times 10^{-6}$ & {$[26,27]$} \\
\hline \hline & $\zeta_{3}$ & -0.00027 & \\
\hline
\end{tabular}



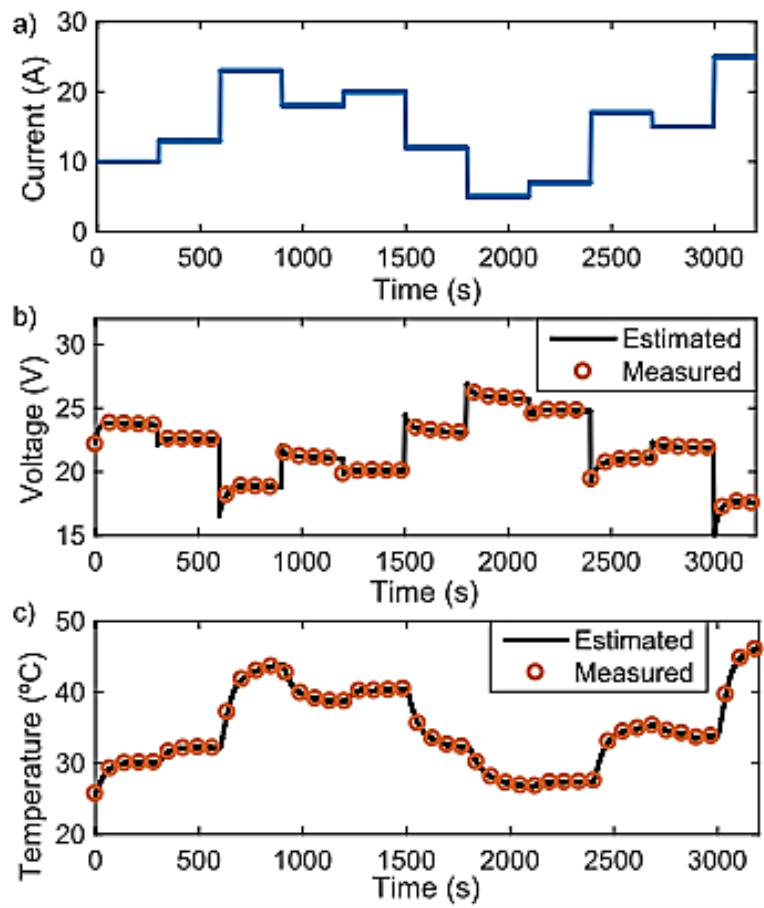

Fig. 12. Verification of the PEMFC model, (a) the utilized current profile, (b) voltage prediction, and (c) temperature prediction.

\section{2) PSO-GA optimization process}

GA and PSO are two well-known metaheuristic algorithms which have been used to resolve a number of different engineering problems. The main reason for using hybrid PSOGA optimization method is to combine their merits. By employing the genetic operators in the structure of PSO, the exploration and exploitation capabilities can be enhanced to some extent. In GA, the information of an individual will be forgotten in case it is not chosen, as opposed to PSO which has memory. On the other hand, PSO might use the resources for weak individuals since it does not have a selection operator. Hence the primary intention to develop PSO-GA is to integrate the social behavior of PSO into the search potential of GA [42]. The flowchart of the utilized PSO-GA algorithm is shown in Fig. 13. As is seen in this figure, first, the optimization problem should be defined by introducing a fitness function as the objective of minimization, the decision variables which are the targeted parameters for estimation, and the search space which is formed by describing the upper and lower limits of each decision variable. In this work, the constructing parameters of the input MFs are considered as the decision variables. To direct the population towards better solutions, a fitness function is required. Regarding the temperature FLC, the main goal is to reach the assigned reference temperature by the power map. In this respect, the integral time-weighted absolute error (ITAE), described in (13), is used as a fitness function for adjusting the parameters of the FLC MFs. The ITAE based tuning leads to much quicker settling time compared to other measures such as integral squared error and integral absolute error.

$\underset{\text { (Decision variables) }}{\min } \int_{1}^{N} t\left|T_{\text {ref }}-T_{s t}\right| d t$ where $t$ is time (s), $T_{r e f}$ is the reference temperature, and $T_{s t}$ is the PEMFC stack temperature. It should be noted that the optimization process of the FLC is performed on the explained PEMFC model since it can damage the real PEMFC. The optimized FLC is then implemented on the test bench to control the real PEMFC.

After defining the optimization problem, the operating parameters of the PSO-GA optimization algorithm should be defined according to TABLE II. Then the problem goes to the main loop of the optimization and the PSO and GA operators try to find the near optimal answer. In this work, separate iterations are introduced for PSO and GA operators inside the main loop to provide more control over them. The PSO algorithm updates the velocity and position of each particle by:

$\left\{\begin{array}{l}v_{i}^{n+1}=C\left[v_{i}^{n}+\alpha_{1} r_{1}\left(p_{\text {best }_{i}}-p_{i}^{n}\right)+\alpha_{2} r_{2}\left(g_{\text {best }}-p_{i}^{n}\right)\right] \\ p_{i}^{n+1}=p_{i}^{n}+v_{i}^{n+1}\end{array}\right.$

where $v_{i}^{n+1}$ is the velocity of particle $i$ at iteration $n+1, C$ is the constriction factor, which ensures the balance between exploration and exploitation of the particles [43], $\alpha_{1}$ and $\alpha_{2}$ are the weighing factors, $r_{1}$ and $r_{2}$ are two random numbers between 0 and $1, p_{i}^{n}$ is the position of particle $i$ at iteration $n$, pbest $_{i}$ is the best position of particle $i$, and gbest is the best position of the swarm. The constriction factor can be formulated by:

$\left\{\begin{array}{l}C=2 /\left|2-\varphi-\sqrt{\varphi^{2}-4 \varphi}\right| \\ \varphi=\alpha_{1}+\alpha_{2}\end{array}\right.$

It is worth mentioning that the value of $\varphi$ should be kept between 4.1 and 4.2 by choosing 2.05 for $\alpha_{1}$ and $\alpha_{2}$ to acquire quality solutions [44].

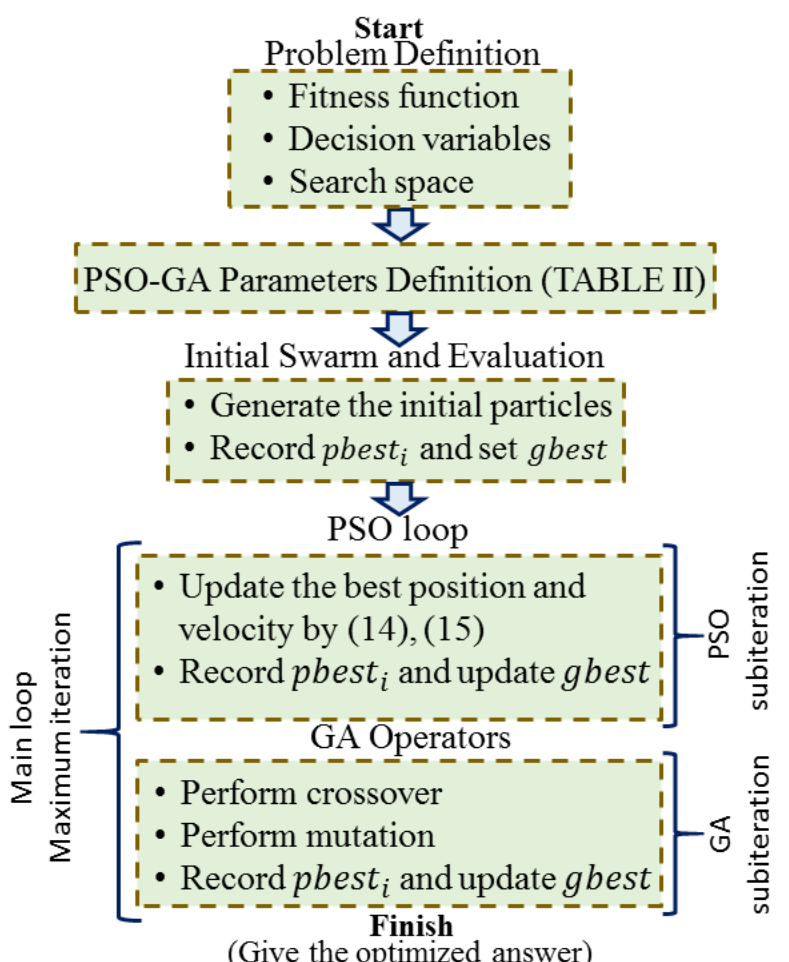

Fig. 13. Flowchart of the PSO-GA algorithm. 
TABLE II

PSO-GA PARAMETERS DEFINITION

\begin{tabular}{ccc}
\hline \hline PSO-GA operators & Definition & Quantity \\
\hline Iter $_{\text {Max }}$ & Maximum iteration & 100 \\
Subiter $_{P S O}$ & Maximum PSO subiteration & 10 \\
Subiter $_{G A}$ & Maximum GA subiteration & 10 \\
$N_{\text {Pop }}$ & Number of population (particles) & 500 \\
$C$ & Constriction factor & 0.729 \\
$C O_{\text {pct. }}$ & Crossover percentage & 0.8 \\
$M u_{\text {pct. }}$ & Mutation percentage & 0.2 \\
\hline \hline
\end{tabular}

Fig. 14 represents the input and output MFs of the designed temperature FLC before and after optimization process. The total number of decision variables are 27. Since the optimization process is performed once, the computational time is not a concern.
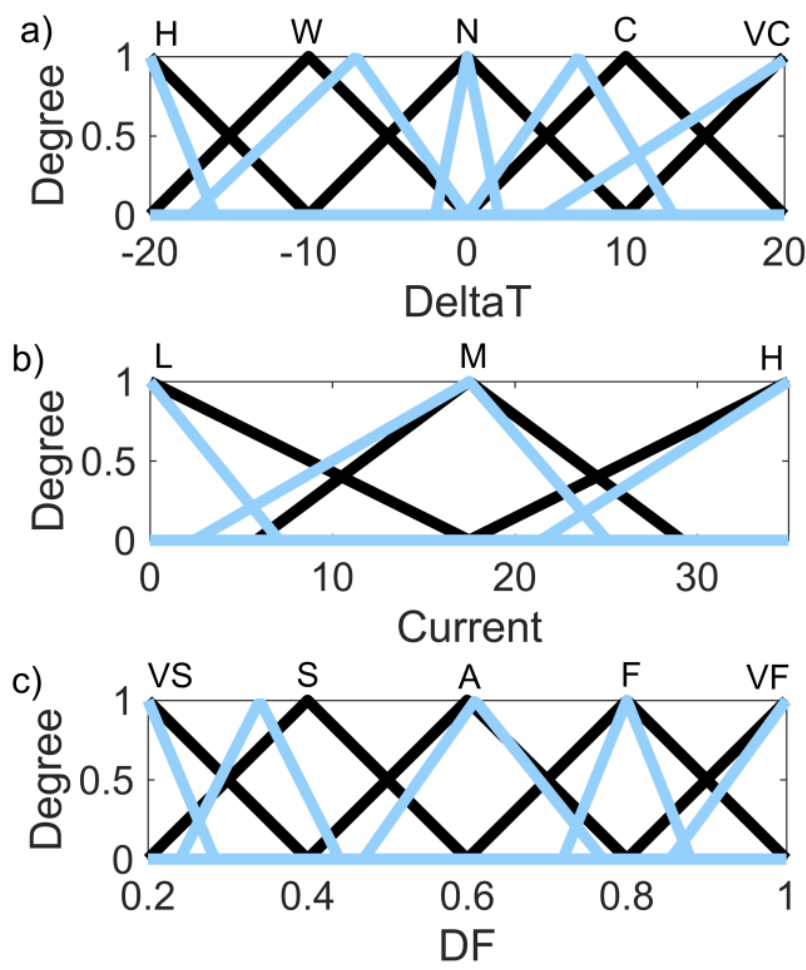

Fig. 14. Input and output MFs before and after tuning.

Fig. 15 represents the results of the tuned FLC performance after the optimization process. The optimization process has been conducted for the indicated current profile in Fig. 15a by using the explained PEMFC model. The reference temperature for each operating current level of Fig. 15a has been obtained from the extracted map of the PEMFC shown in Fig. 7. According to Fig. 15b, the best fitness value of the fitness function levels off after almost 25 iterations and the mean value of the fitness reaches the best value after about 85 iterations. Fig. $15 \mathrm{c}$ represents that the tuned FLC can reach the determined referenced temperature in an acceptable time. Moreover, the behavior of the cooling fan duty factor, which causes this temperature evolution, is shown in Fig. 15c.
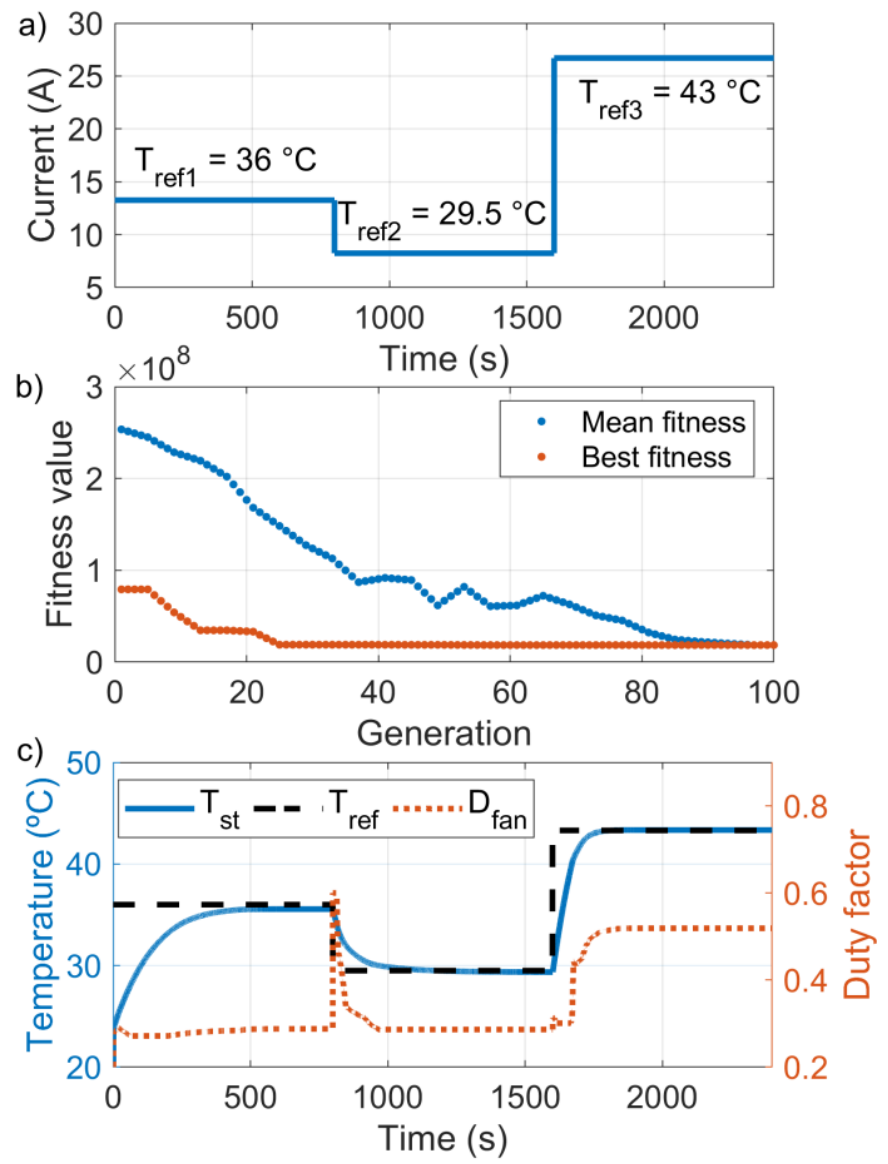

Fig. 15. Optimization results of the FLC tuning, a) the employed current profile for the tuning process, b) the minimization trend of the objective function, and c) the test of the optimized FLC for reaching the reference temperature.

\section{EXPERIMENT AND RESULTS ANALYSIS}

Two assessment tests are designed to show the efficiency of the proposed systemic management. The first test deals with supplying a constant power profile, and the second test copes with variable power profile. In each stage, the performance of the proposed approach is compared with the commercial controller from manufacturer. Fig. 16 represents the stabilization process of the PEMFC system for supplying a constant power of $380 \mathrm{~W}$. From Fig. 16a, it is observed that by using the proposed thermal scheme, a lower current level is required to meet the demanded power, compared to the manufacturer controller. It is worth noting that achieving the same level of power by using different current levels in this test highlights the importance of the thermal management. According to Fig. 16b, the manufacturer controller tends to keep the stack temperature at a higher level than the proposed approach. This higher temperature can result in a dryer membrane and less available oxygen for reaction. Moreover, the proposed systemic control consumes less hydrogen (4.47 SLPM) for providing the requested constant power profile as opposed to the manufacturer controller (5.35 SLPM). 


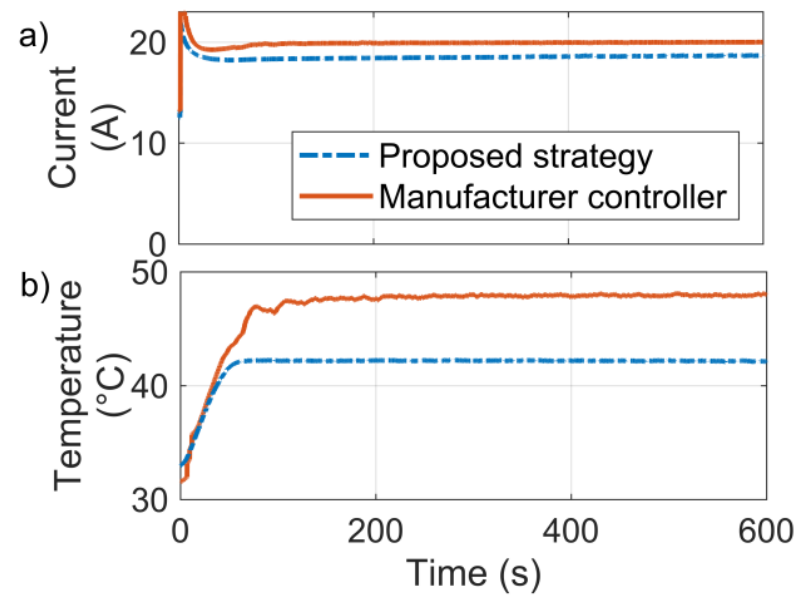

Fig. 16. Corresponded current (a), and temperature (b) for supplying a 380W constant power.

The second test, which belongs to a variable power profile, is shown in Fig. 17. This low dynamic profile contains various high and low levels and indicates more clearly the performance of the proposed thermal strategy in different conditions.

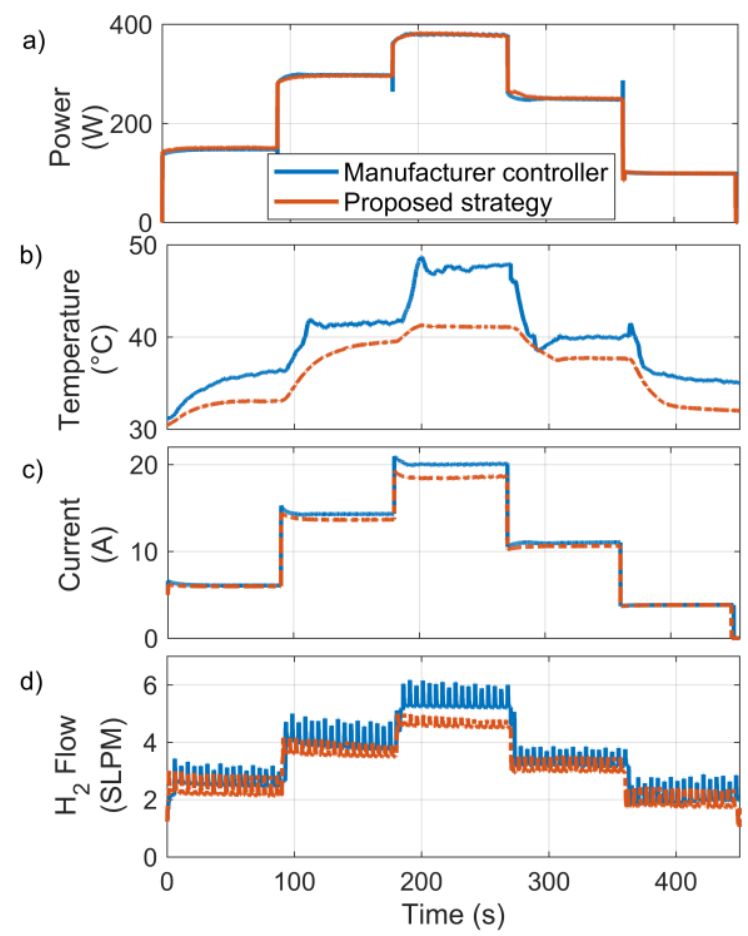

Fig. 17. Variable power profile test (a) along with its corresponded temperature (b), current (c), and $\mathrm{H}_{2}$ consumption (d).

Fig. 17a indicates that both of controllers are able to provide the demanded power. However, the temperature evolution of the PEMFC stack by each of the controllers is different as represented in Fig. 17b. The required current levels for supplying the power are also different, as shown in Fig. 17c. Both of the controllers tend to use the same current in low power levels. However, in high power levels, the proposed strategy uses less current to meet the power. The effect of using a lower current level to satisfy the requested power can be embraced by checking the hydrogen consumption, which is represented in Fig. 17d. It is observed that the hydrogen consumption achieved by utilizing the proposed FLC controller is lower than the manufacturer controller, specifically in highpower regions. Looking more carefully at Fig. 17, it can be seen that although the drawn current from the stack is almost the same in low-current regions (Fig. 17c), the hydrogen consumption is different. This is mainly due to the fact that the temperature levels are clearly different (Fig. 17b) in low-current regions. It is worth noting that this difference in temperature levels implies that the duty factor of the fan, which is responsible both for cooling the system and providing the necessary oxygen for the reactions, is also variable. Moreover, this result justifies the presented behavior of the open cathode PEMFC in Fig. 7 of the paper where the current levels are remarkably near to the minimum current while the temperature level changes more distinctly in low-power region.

Fig. 18 represents the comparison of the total hydrogen consumption of the discussed constant and variable power profiles for the case of manufacturer controller and the proposed systemic strategy. According to this figure, the proposed strategy of this work is able to decrease the hydrogen consumption of the PEMFC system by $13 \%$ and $16 \%$ for the case of constant and variable power profiles respectively.

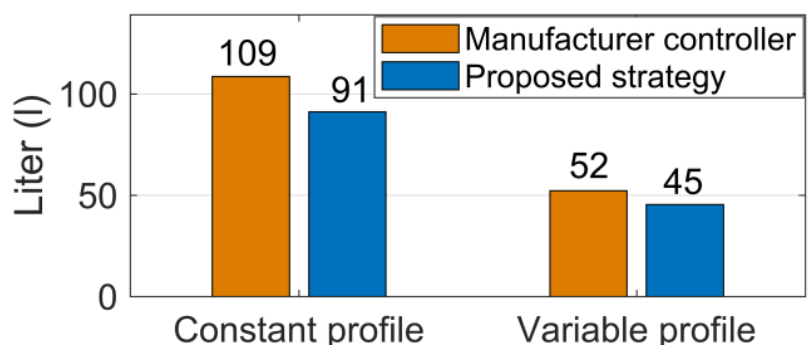

Fig. 18: Hydrogen consumption comparison of the PEMFC system for different scenarios.

\section{CONCLUSION}

In this manuscript, a systemic management strategy is proposed to enhance the efficiency of an open cathode PEMFC system in different requested power levels. This strategy focuses on the usage of 3D mapping to determine the reference temperature of the control scheme. In this respect, a number of experiments are conducted to get a $3 \mathrm{D}$ power map for various stack temperatures and currents. This power map provides an efficient path based on the stack temperature and the current level of the PEMFC system and determines the reference temperature for each particular demanded power level from the system. Finally, an optimized FLC is used to achieve the defined reference temperature as the current of the PEMFC is being controlled by a PI controller. The obtained results from the conducted experiments highlight the satisfying performance of the proposed methodology by improving the system efficiency up to $13 \%$ and $16 \%$ for constant and variable power profiles respectively. While this manuscript has demonstrated the potential of the suggested systemic management strategy, some opportunities for extending the scope of this paper remain as follows: 
- Integrating the proposed methodology into the design of an energy management strategy for a fuel cell hybrid electric vehicle.

- Integrating an online system identification method to update the $3 \mathrm{D}$ power map to adapt to the performance drifts of the PEMFC system.

- Carrying out an ageing study of the PEMFC while using the suggested current and temperature control.

\section{REFERENCES}

J. Snoussi, S. B. Elghali, M. Benbouzid, and M. F. Mimouni, "Optimal Sizing of Energy Storage Systems Using FrequencySeparation-Based Energy Management for Fuel Cell Hybrid Electric Vehicles," IEEE Transactions on Vehicular Technology, vol. 67, pp. 9337-9346, 2018.

[2] H. Pei, K. Meng, H. Chang, Y. Zhang, J. Shen, Z. Tu, et al., "Performance improvement in a proton exchange membrane fuel cell with separated coolant flow channels in the anode and cathode," Energy Conversion and Management, vol. 187, pp. 76-82, 2019/05/01/ 2019.

[3] M. Karthikeyan, P. Karthikeyan, M. Muthukumar, V. Magesh Kannan, K. Thanarajan, T. Maiyalagan, et al., "Adoption of novel porous inserts in the flow channel of pem fuel cell for the mitigation of cathodic flooding," International Journal of Hydrogen Energy, 2019/09/12/ 2019.

[4] O. S. Ijaodola, Z. El- Hassan, E. Ogungbemi, F. N. Khatib, T. Wilberforce, J. Thompson, et al., "Energy efficiency improvements by investigating the water flooding management on proton exchange membrane fuel cell (PEMFC)," Energy, vol. 179, pp. 246-267, 2019/07/15/ 2019 .

[5] M. Pourabdollah, B. Egardt, N. Murgovski, and A. Grauers, "Convex Optimization Methods for Powertrain Sizing of Electrified Vehicles by Using Different Levels of Modeling Details," IEEE Transactions on Vehicular Technology, vol. 67, pp. 1881-1893, 2018.

[6] F. Odeim, J. Roes, and A. Heinzel, "Power Management Optimization of a Fuel Cell/Battery/Supercapacitor Hybrid System for Transit Bus Applications," IEEE Transactions on Vehicular Technology, vol. 65, pp. 5783-5788, 2016.

[7] H. Chen, B. Liu, T. Zhang, and P. Pei, "Influencing sensitivities of critical operating parameters on PEMFC output performance and gas distribution quality under different electrical load conditions," Applied Energy, vol. 255, p. 113849, 2019/12/01/ 2019.

[8] G. Zhang and K. Jiao, "Multi-phase models for water and thermal management of proton exchange membrane fuel cell: A review," Journal of Power Sources, vol. 391, pp. 120-133, 2018/07/01/2018. J. Chen, Z. Liu, F. Wang, Q. Ouyang, and H. Su, "Optimal Oxygen Excess Ratio Control for PEM Fuel Cells," IEEE Transactions on Control Systems Technology, vol. 26, pp. 1711-1721, 2018.

[10] C. Yan, J. Chen, H. Liu, and H. Lu, "Model-based Fault Tolerant Control for the Thermal Management of PEMFC Systems," IEEE Transactions on Industrial Electronics, pp. 1-1, 2019.

[11] L. Yin, Q. Li, T. Wang, L. Liu, and W. Chen, "Real-time thermal Management of Open-Cathode PEMFC system based on maximum efficiency control strategy," Asian Journal of Control, pp. 1- 15, 2019.

[12] S. Strahl and R. Costa-Castelló, "Temperature control of opencathode PEM fuel cells," IFAC-PapersOnLine, vol. 50, pp. 1108811093, 2017/07/01/ 2017.

[13] S. Strahl, A. Husar, P. Puleston, and J. Riera, "Performance Improvement by Temperature Control of an Open-Cathode PEM Fuel Cell System," Fuel Cells, vol. 14, pp. 466-478, 2014.

[14] Y. Nagai, J. Eller, T. Hatanaka, S. Yamaguchi, S. Kato, A. Kato, et al., "Improving water management in fuel cells through microporous layer modifications: Fast operando tomographic imaging of liquid water," Journal of Power Sources, vol. 435, p. 226809, 2019/09/30/ 2019.

[15] G. Dotelli, R. Ferrero, P. G. Stampino, S. Latorrata, and S. Toscani, "PEM Fuel Cell Drying and Flooding Diagnosis With Signals
Injected by a Power Converter," IEEE Transactions on Instrumentation and Measurement, vol. 64, pp. 2064-2071, 2015.

[16] L. Sun, G. Li, Q. S. Hua, and Y. Jin, "A Hybrid Paradigm Combining Model-Based and Data-Driven Methods for Proton Exchange Membrane Fuel Cell Stack Cooling Control," Renewable Energy, 2019/09/17/ 2019.

[17] V. Liso, M. P. Nielsen, S. K. Kær, and H. H. Mortensen, "Thermal modeling and temperature control of a PEM fuel cell system for forklift applications," International Journal of Hydrogen Energy, vol. 39, pp. 8410-8420, 2014.

[18] D. O'Keefe, M. Y. El-Sharkh, J. C. Telotte, and S. Palanki, "Temperature dynamics and control of a water-cooled fuel cell stack," Journal of Power Sources, vol. 256, pp. 470-478, 2014.

[19] A. Fly and R. H. Thring, "Temperature regulation in an evaporatively cooled proton exchange membrane fuel cell stack," International Journal of Hydrogen Energy, vol. 40, pp. 11976$11982,2015$.

[20] Y. Saygili, I. Eroglu, and S. Kincal, "Model based temperature controller development for water cooled PEM fuel cell systems," International Journal of Hydrogen Energy, vol. 40, pp. 615-622, 2015.

[21] J. Han, J. Park, and S. Yu, "Control strategy of cooling system for the optimization of parasitic power of automotive fuel cell system," International Journal of Hydrogen Energy, vol. 40, pp. 1354913557, 2015.

[22] J. Han, S. Yu, and S. Yi, "Advanced thermal management of automotive fuel cells using a model reference adaptive control algorithm," International Journal of Hydrogen Energy, vol. 42, pp. 4328-4341, 2017.

[23] D. Li, C. Li, Z. Gao, and Q. Jin, "On active disturbance rejection in temperature regulation of the proton exchange membrane fuel cells," Journal of Power Sources, vol. 283, pp. 452-463, 2015.

[24] N. Lotfi, H. Zomorodi, and R. G. Landers, "Active disturbance rejection control for voltage stabilization in open-cathode fuel cells through temperature regulation," Control Engineering Practice, vol. 56, pp. 92-100, 2016.

[25] Y. Devrim, H. Devrim, and I. Eroglu, "Development of 500 W PEM fuel cell stack for portable power generators," International Journal of Hydrogen Energy, vol. 40, pp. 7707-7719, 2015.

[26] K. Ou, W.-W. Yuan, M. Choi, S. Yang, and Y.-B. Kim, "Performance increase for an open-cathode PEM fuel cell with humidity and temperature control," International Journal of Hydrogen Energy, vol. 42, pp. 29852-29862, 2017.

[27] Y.-X. Wang, F.-F. Qin, K. Ou, and Y.-B. Kim, "Temperature Control for a Polymer Electrolyte Membrane Fuel Cell by Using Fuzzy Rule," IEEE Transactions on Energy Conversion, vol. 31, pp. 667-675, 2016.

[28] Q. Li, T. Wang, C. Dai, W. Chen, and L. Ma, "Power Management Strategy Based on Adaptive Droop Control for a Fuel Cell-BatterySupercapacitor Hybrid Tramway," IEEE Transactions on Vehicular Technology, vol. 67, pp. 5658-5670, 2018.

[29] Y. Han, Q. Li, T. Wang, W. Chen, and L. Ma, "Multisource Coordination Energy Management Strategy Based on SOC Consensus for a PEMFC-Battery-Supercapacitor Hybrid Tramway," IEEE Transactions on Vehicular Technology, vol. 67, pp. 296-305, 2018.

[30] S. Ziaeinejad, Y. Sangsefidi, and A. Mehrizi-Sani, "Fuel Cell-Based Auxiliary Power Unit: EMS, Sizing, and Current Estimator-Based Controller," IEEE Transactions on Vehicular Technology, vol. 65, pp. 4826-4835, 2016.

[31] M. Higuita Cano, M. I. A. Mousli, S. Kelouwani, K. Agbossou, M. Hammoudi, and Y. Dubé, "Improving a free air breathing proton exchange membrane fuel cell through the Maximum Efficiency Point Tracking method," Journal of Power Sources, vol. 345, pp. 264-274, 2017.

[32] N. Karami, L. E. Khoury, G. Khoury, and N. Moubayed, "Comparative study between P\&amp;O and incremental conductance for fuel cell MPPT," in International Conference on Renewable Energies for Developing Countries 2014, 2014, pp. 1722.

[33] P.-Y. Chen, K.-N. Yu, H.-T. Yau, J.-T. Li, and C.-K. Liao, "A novel variable step size fractional order incremental conductance algorithm to maximize power tracking of fuel cells," Applied Mathematical Modelling, vol. 45, pp. 1067-1075, 2017/05/01/2017. 
M. Kandidayeni, A. Macias, A. A. Amamou, L. Boulon, S. Kelouwani, and H. Chaoui, "Overview and benchmark analysis of fuel cell parameters estimation for energy management purposes," Journal of Power Sources, vol. 380, pp. 92-104, 2018.

[35] M. Kandidayeni, A. A. Amamou, L. Boulon, and S. Kelouwani, "Comparative Analysis of Two Online Identification Algorithms in a Fuel Cell System," Fuel Cells, vol. 0, 2018.

[36] S. Ahmadi, S. Abdi, and M. Kakavand, "Maximum power point tracking of a proton exchange membrane fuel cell system using PSO-PID controller," International Journal of Hydrogen Energy, vol. 42, pp. 20430-20443, 2017/08/10/ 2017.

[37] K. Ettihir, L. Boulon, and K. Agbossou, "Optimization-based energy management strategy for a fuel cell/battery hybrid power system," Applied Energy, vol. 163, pp. 142-153, 2016/02/01/ 2016.

[38] K. Ettihir, L. Boulon, M. Becherif, K. Agbossou, and H. S. Ramadan, "Online identification of semi-empirical model parameters for PEMFCs," International Journal of Hydrogen Energy, vol. 39, pp. 21165-21176, 2014/12/12/ 2014.

[39] A. Macias, "Online Identification for Energy Management of MultiStack Systems," M.S. thesis, Université du Québec à Trois-Rivières, Canada, 2018.

[40] C. Restrepo, T. Konjedic, A. Garces, J. Calvente, and R. Giral, "Identification of a Proton-Exchange Membrane Fuel Cell's Model Parameters by Means of an Evolution Strategy," IEEE Transactions on Industrial Informatics, vol. 11, pp. 548-559, 2015.

[41] C. Wang, M. H. Nehrir, and S. R. Shaw, "Dynamic Models and Model Validation for PEM Fuel Cells Using Electrical Circuits," IEEE Transactions on Energy Conversion, vol. 20, pp. 442-451, 2005.

[42] H. Garg, "A hybrid PSO-GA algorithm for constrained optimization problems," Applied Mathematics and Computation, vol. 274, pp. 292-305, 2016.

[43] M. Clerc and J. Kennedy, "The particle swarm - explosion, stability, and convergence in a multidimensional complex space," IEEE Transactions on Evolutionary Computation, vol. 6, pp. 58-73, 2002.

[44] G. Abbas, J. Gu, U. Farooq, M. U. Asad, and M. El-Hawary, "Solution of an Economic Dispatch Problem Through Particle Swarm Optimization: A Detailed Survey - Part I," IEEE Access, vol. 5, pp. 15105-15141, 2017.

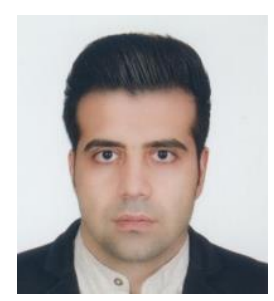

Mohsen Kandidayeni (S'18) is currently a $\mathrm{PhD}$ student at Université du Québec à Trois-Rivières (UQTR), working on energy-related topics such as Hybrid Electric Vehicles, Fuel cell systems, Energy management, Multiphysics systems, Modeling and Control. He graduated from Arak University with a master's degree in Mechatronics in 2014. His research interests are in the area of Renewable Energy, Fuel Cell, Transportation, Intelligent Transport Systems, Vehicular Systems Control, Hybrid Electric and Electric Vehicles.

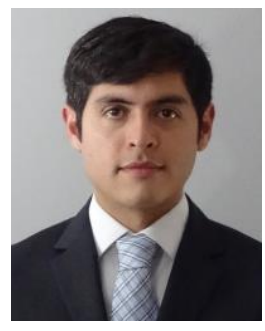

Alvaro Macias F. (M'17) was born in Mexico City, in 1992. He received the B.S. degree in mechatronics engineering from Tec de Monterrey, Guadalajara, Mexico, in 2015 and the M.S. degree in electrical engineering from Université du Québec à TroisRivières, Canada, in 2018. He is currently pursuing the Ph.D. degree in electrical engineering at Université du Québec à Trois-Rivières, Canada. From 2015 to 2016, he worked as Research and Development in the Centro de Investigación y de Estudios Avanzados del Instituto Politécnico Nacional, Mexico. His current research interest includes the development of energy management strategies for fuel cell systems, passive and active system configuration, and fuel cell modeling.

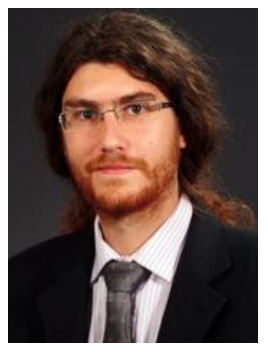

Loïc Boulon (M'10, SM'16) received the master's degree in electrical and automatic control engineering from the University of Lille (France), in 2006. Then, he obtained a $\mathrm{PhD}$ in electrical engineering from University of Franche-Comté (France). Since 2010, he is a professor at Université du Québec à TroisRivières (Canada) and he works at the Hydrogen Research Institute (Full Professor since 2016). His work deals with modeling, control and energy management of multiphysics systems. His research interests include hybrid electric vehicles, energy and power sources (especially battery in cold weather operation), and fuel cell systems. He has published more than 100 scientific papers in peer-reviewed international journals and international conferences.

In 2015, Loïc Boulon was general chair of the IEEE-Vehicular Power and Propulsion Conference in Montréal (QC, Canada). Prof. Loïc Boulon is VPMotor Vehicles of the IEEE Vehicular Technology Society and he is the holder of the Canada Research Chair in Energy Sources for the Vehicles of the future.

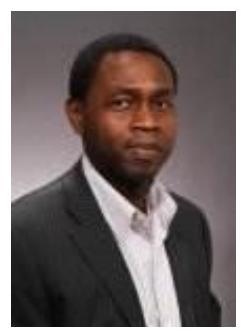

Sousso Kelouwani (M'00-SM'17) received the B.S. and the M.Sc.A. degrees from Université du Québec à Trois-Rivières, Trois-Rivières, QC, Canada, in 2000 and 2002, respectively, and the Ph.D. degree (automation and systems) from École Polytechnique de Montréal, Montréal, QC, Canada, in 2010, all in electrical engineering. Holder of the Industrial Research Chair DIVEL in Intelligent Navigation of Autonomous Industrial Vehicles, Sousso Kelouwani is a full professor of Mechatronics at the Department of Mechanical Engineering at UQTR (since 2018). Before starting his doctoral studies, he worked in research and development in the field of cell phone application optimization for Cilys 53 inc. (2002-2005) and Openwave inc. (2005-2006). Holder of three patents in the United States, his research interest focuses on the optimization of energy systems for vehicular applications, advanced driving assistance techniques, eco-energy navigation of autonomous vehicles, hybridization of energy sources for vehicles with low ecological impact (battery, fuel cell, hydrogen generator, etc.) in harsh weather conditions. In 2017, he received the Environment Award of the Grand Prix for Excellence in Transport from the Quebec Transportation Association (AQTr) for the development of a hydrogen range extender based on a hydrogen generator for electric vehicles. He was also a recipient of the Canada Governor General's Gold Medal in 2000. Moreover, he has worked with several Canadian transportation companies to develop intelligent, energy-efficient and driverless vehicles. 